\title{
Analysis a DSP Implementation and Experimental Validation of a Loss Minimization Algorithm Applied to Permanent Magnet Synchronous Motor Drives
}

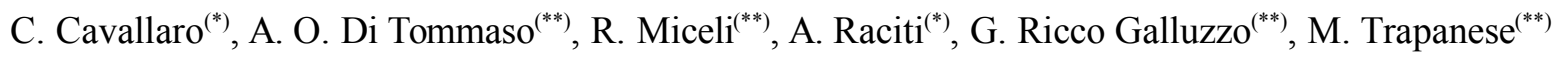 \\ ${ }^{(*)}$ Dept. of Electrical, Electronic and Systems Engineering, University of Catania \\ Viale A. Doria, 6 - 95125 Catania, Italy, Tel. +39 0957382323 Fax +39095 339535 \\ E-mail: ccavalla@diees.unict.it - araciti@diees.unict.it \\ ${ }^{(* *)}$ Department of Electrical Engineering, University of Palermo \\ Viale delle Scienze - 90128 Palermo, Italy, Tel. +390916615285 Fax +39091488452 \\ E-mail: ditommaso@diepa.unipa.it - miceli@diepa.unipa.it - ricco@diepa.unipa.it - trapanese@diepa.unipa.it
}

\begin{abstract}
In this paper a new loss minimization control algorithm for inverter-fed permanent-magnet synchronous motors (PMSM), which allows to reduce the power losses of the electric drive without penalty on its dynamic performances, is analyzed, experimentally realized and validated. In particular, after a brief recall of two loss minimization control strategies (the "search control" and the "loss-model control"), both a modified dynamic model of the PMSM, which takes into account the iron losses, and a "loss-model" control strategy, are treated. Experimental tests on a specific PMSM drive employing the proposed loss minimization algorithm were performed aiming to validate the actual implementation. The main results of these tests confirm that the dynamic performances of the drive are maintained, and enhancement up to $3.5 \%$ of the efficiency can be reached in comparison to the PMSM drive equipped with a more traditional control strategy.
\end{abstract}

Index Terms-Permanent magnet synchronous motor, motor drives, variable speed drives, control systems, efficiency improvement.

\section{INTRODUCTION}

Today particular emphasis is addressed towards environmental pollution. In this respect, the link between any wasted energy and the consequent negative fall-down as increase of the environmental pollution has been well demonstrated. In particular, this applies to electrical consumption, which involves complicated industrial processes for the electric energy development. Thus long-term operations of electrical drives, which are a noticeable loadconsuming equipment, like those for electric vehicle propulsion or industrial apparatuses (compressors, fans, pumps, machine tools, etc.), are expected to have high efficiency as one of the most important figures. The whole efficiency depends on the single efficiency of the different components of the electric drives. It is worth noting that by using optimal control strategies it is possible to reduce the losses of the electric drives, without loss of the dynamic performances of the drive.

Permanent magnet synchronous motors (PMSMs) are widely used in industrial drive applications for their high performances. The main reasons rely on their optimal characteristics, which are, for example, higher efficiency and higher power-weight ratio than $\mathrm{dc}$ and induction motors. PMSMs are convenient because they have a loss-free rotor, and power losses are mainly related to the stator windings and the stator core. The ratio of the copper and iron power losses is a key issue in determining the maximum efficiency point as function of the mechanical load on the motor shaft. In the case of constant-speed motors fed by the main, the motor designer performs a trade-off in order to obtain a maximum efficiency at given load conditions, according to the user requirements. Unfortunately, this advantageous condition is no longer true as long as the motors operate at variable-torque and variable-speed.

This paper deals with a control algorithm, which is able to reduce the losses (copper and iron losses) of interior permanent magnet synchronous motor drives, through an optimal management of the current space vector in the stator winding, in the case of variable speed and variable torque applications. In particular, after a brief recall of two loss minimization control strategies [1], [2], [3] (the "search control" and the "loss-model control"), both a modified dynamic model of the PMSM that takes into account also the iron losses and a "loss-model" control strategy, implemented by the authors [4] are treated. The control algorithm allows determining the optimal current space vector according to the operating speed and the load conditions. The exploited approach can be applied to machines with both salient and non-salient rotor types, but the best results are reached with the latter ones.

Experimental tests on a specific PMSM drive employing the proposed loss minimization algorithm have shown that its dynamic performances are maintained, and enhancement up to $3.5 \%$ of the efficiency can be reached in comparison to the PMSM drive equipped with a more traditional control strategy $\left(i_{d}=0\right)$.

\section{II.LOSS MINIMIZATION CONTROL STRATEGIES}

Loss minimization control strategies have been extensively investigated in literature [5], [6], [7], [8], and [9]. They can fundamentally be summarized into two main categories: "loss model control" strategies and "search control" ones. The "loss model control" technique is based on the development of a mathematical model, which allows estimating the energy losses of the motor. By expressing the losses as a function of the control variables of the electrical drive, then it is possible 
to impose an operating condition in order to minimize the whole electrical loss [1].

On the other hand, the "search control" algorithm is based on a searching procedure that can successful individuate a maximum efficiency operating point [2]. The "search control" algorithm has the advantage that there is no need to know the mathematical model of the motor and its parameters. A major drawback of such a technique is that instability of the drive can arise, thus requiring an additional stabilization network [6]. Moreover, additional devices (as voltage and current transducers) are required on the dc-link in order to obtain a measurement of the power absorption of the electrical drive. These disadvantages have a fall-down in an increase of both the system complexity and costs, and consequently discourage any application in the field of industrial drives.

\section{PMSM DYNAMIC MODEL WITH IRON LOSSES}

As shown in [4], under the basic hypotheses that the spatial distribution of the magnetic flux in the air gap is sinusoidal and the magnetic circuit is linear, the PMSM dynamic d- and q-axis equivalent circuits, which accounts for the iron losses, can be drawn as it is shown in Fig. 1. With reference to Fig. 1 , the state space equations of the dynamic model of a PMSM, which takes into account also the iron losses, is given by the following relations:

$$
\begin{aligned}
& \frac{d i_{d}}{d t}=\frac{1}{L_{l d}}\left(v_{d}-R i_{d}-L_{m d} \frac{d i_{o d}}{d t}+L_{q} P \omega_{r} i_{o q}\right) \\
& \frac{d i_{q}}{d t}=\frac{1}{L_{l q}}\left(v_{q}-R i_{q}-L_{m q} \frac{d i_{o q}}{d t}-L_{d} P \omega_{r} i_{o d}-\lambda_{P M} P \omega_{r}\right)
\end{aligned}
$$

$$
\frac{d \omega_{r}}{d t}=\frac{1}{J}\left[T_{e}-C \operatorname{Sign}\left(\omega_{r}\right)-F \omega_{r}-T_{m}\right]
$$

$\frac{d \theta_{r}}{d t}=\omega_{r}=\frac{\omega}{P}$

where

$$
\begin{aligned}
& i_{o d}=i_{d}-i_{c d}, \quad i_{o q}=i_{q}-i_{c q} \\
& i_{c d}=\frac{-\omega k L_{d} i_{o q}+L_{m d} \frac{d i_{o d}}{d t}}{R_{c}} \\
& i_{c q}=\frac{\omega\left(\lambda_{P M}+L_{d} i_{o d}\right)+L_{m q} \frac{d i_{o q}}{d t}}{R_{c}}
\end{aligned}
$$

$T_{e}=\frac{3}{2} P\left[\lambda_{P M} i_{o q}+\left(L_{m d}-L_{m q}\right) i_{o d} i_{o q}\right]$

\section{LosS MinimizATION ALGORITHM}

The power losses in a PMSM are copper and iron losses in the stator, mechanical losses, and additional losses. The last ones are related with both the copper and iron, and here are neglected for the sake of simplicity, and also because, being their values difficult to estimate, are normally evaluated in percentage of the rated power. A more work-oriented analysis
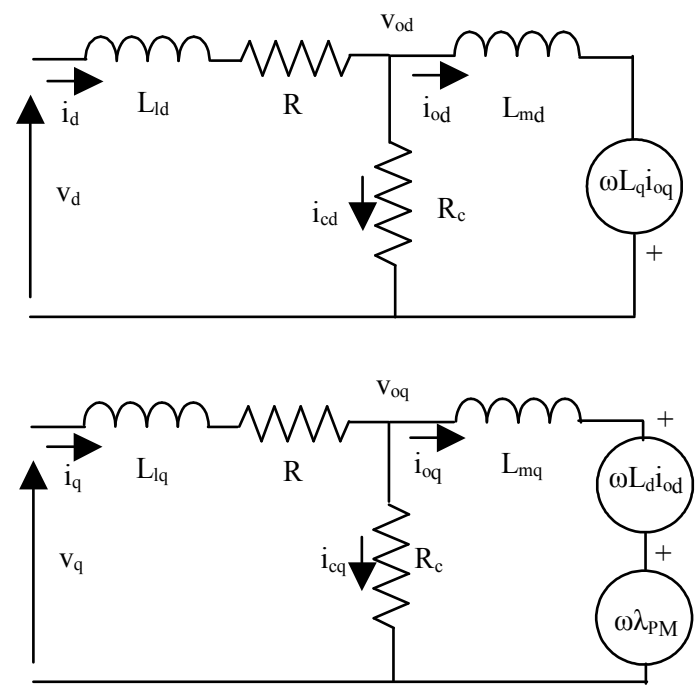

Fig. 1. Dynamic d-q axis equivalent circuits of a PMSM.

can be done by splitting these considered losses into two categories, namely, controllable and uncontrollable losses.

The copper losses, which are determined by the fundamental harmonic component of the stator current, and the iron losses, which are determined by the fundamental harmonic components of the total linkage flux, belong to the first type (in turn, these losses depend on the controllable variables of the motor). Unlike the above quantities, copper and iron losses that are caused by the higher harmonic components, along with the mechanical losses, belong to the uncontrollable ones.

By referring equations (1-2) and (5-6) to a steady state condition, it is possible to find a mathematical expression of the power losses caused by the fundamental harmonic of the current in the windings $\left(W_{C_{u}}\right)$, and also of the power losses caused by the fundamental harmonic of the total linkage flux in the iron stack $\left(W_{F e}\right)$. In turn, the controllable electrical losses can be expressed as a function of the $i_{\text {od }}$ and $i_{\text {oq }}$ current components and also of the electrical speed, $\omega=P \omega_{r}$.

$$
\begin{aligned}
& W_{C u}\left(i_{o d}, i_{o q}, \omega\right)=\frac{3}{2} R\left(i_{d}^{2}+i_{q}^{2}\right)= \\
& \quad \frac{3}{2} R\left\{\left(i_{o d}-\frac{\omega L_{q} i_{o q}}{R_{c}}\right)^{2}+\left(i_{o q}+\frac{\omega\left(\lambda_{P M}+L_{d} i_{o d}\right)}{R_{c}}\right)^{2}\right\}
\end{aligned}
$$




$$
\begin{aligned}
& W_{F e}\left(i_{o d}, i_{o q}, \omega\right)=\frac{3}{2} R_{c}\left(i_{c d}^{2}+i_{c q}^{2}\right)= \\
& \frac{3}{2} \frac{\omega^{2}}{R_{c}}\left[\left(L_{q} i_{o q}\right)^{2}+\left(\lambda_{P M}+L_{d} i_{o d}\right)^{2}\right]
\end{aligned}
$$

Accordingly, the total electrical losses are:

$$
W_{C}\left(i_{o d}, i_{o q}, \omega\right)=W_{C u}+W_{F e}
$$

The controllable losses in steady-state condition can be obtained by combining relation (7) and (10). The result is a relation that expresses the power losses of the motor as function of the electromagnetic torque $T_{\mathrm{e}}$, the direct axis current component $i_{\mathrm{od}}$ and the angular speed $\omega_{\mathrm{r}}$. In detail:

$$
W_{C}\left(i_{o d}, T_{e}, \omega\right)=W_{C u}\left(i_{o d}, T_{e}, \omega\right)+W_{F e}\left(i_{o d}, T_{e}, \omega\right)
$$

A simple consideration can be carried out based on inspection of relation (11): at fixed values of both $T_{\mathrm{e}}$ and $\omega$, the total controllable losses only depend on the $i_{\text {od }}$ value, then can be minimized by controlling the current space vector. The determination of the minimum of (11) can be pursued by adopting an iterative numerical algorithm. The result of such a search is the minimum of the function (11) and the correspondent value of the $i_{d}$ current, being fixed the load torque and the angular speed. In particular, in this case an interval-reduction algorithm has been chosen [10], being it a useful and highly efficient calculation procedure for all those functions that present in the searching interval only a local minimum. The flowchart of this algorithm is shown in Fig. 2.

\section{V.EXPERIMENTAL TEST BENCH}

A test bench for the validation of the loss minimization algorithm (LMA) has been set up by implementing the proposed control system in the electrical drive laboratory at the Department of Electrical Engineering, the University of Palermo. The test bench is constituted by a controlled brake, a three-phase power analyzer with $200 \mathrm{kHz}$ bandwidth, and

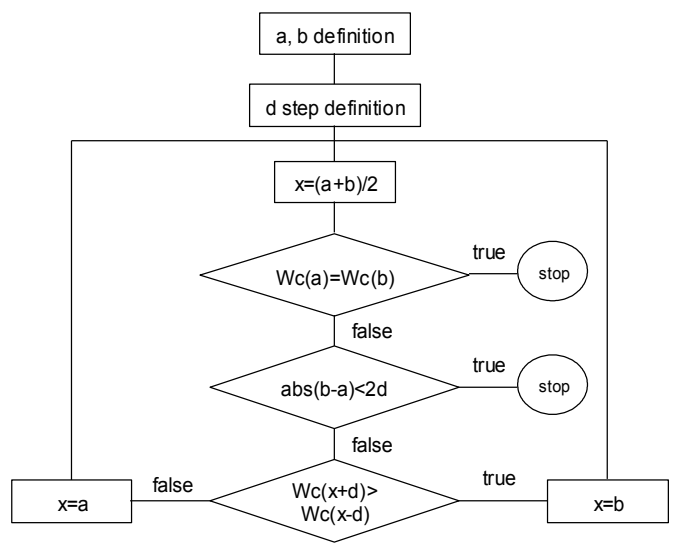

Fig. 2. Flow chart of the minimization algorithm. $a$ and $b$ are the search interval limits, $d$ is the search step, $x$ the medium test point of the interval $(a, b), W_{c}(x)$ are the power losses. the PMSM electrical drive under test. A simplified block diagram of the test bench is presented in Fig. 3. A photo of the test bench and some particulars are shown in Fig. 4 (a) and (b).

In detail, the PMSM electrical drive under test is composed by a radial magnetized PMSM, an IGBT-based converter, and a dSPACE rapid prototyping system that drives the IGBT converter according to a field oriented control strategy. In Fig. 5 the block diagram of the PMSM electrical drive is depicted. In this block diagram the "speed controller" determines the required motor torque according to the speed

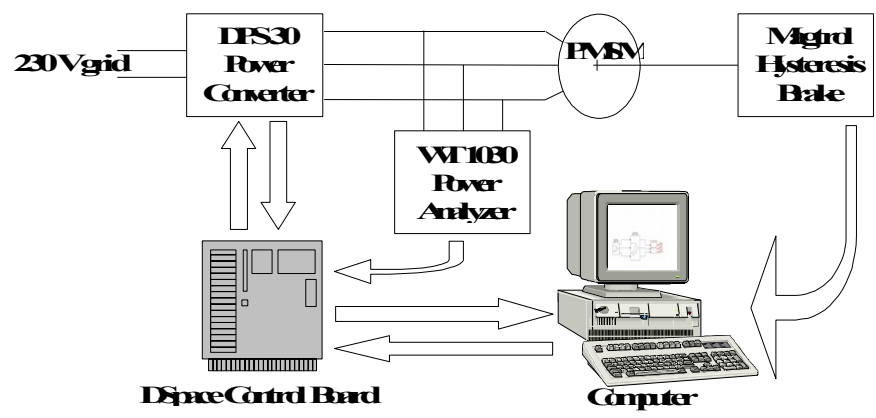

Fig. 3. Simplified schematic of the PMSM drive test bench.
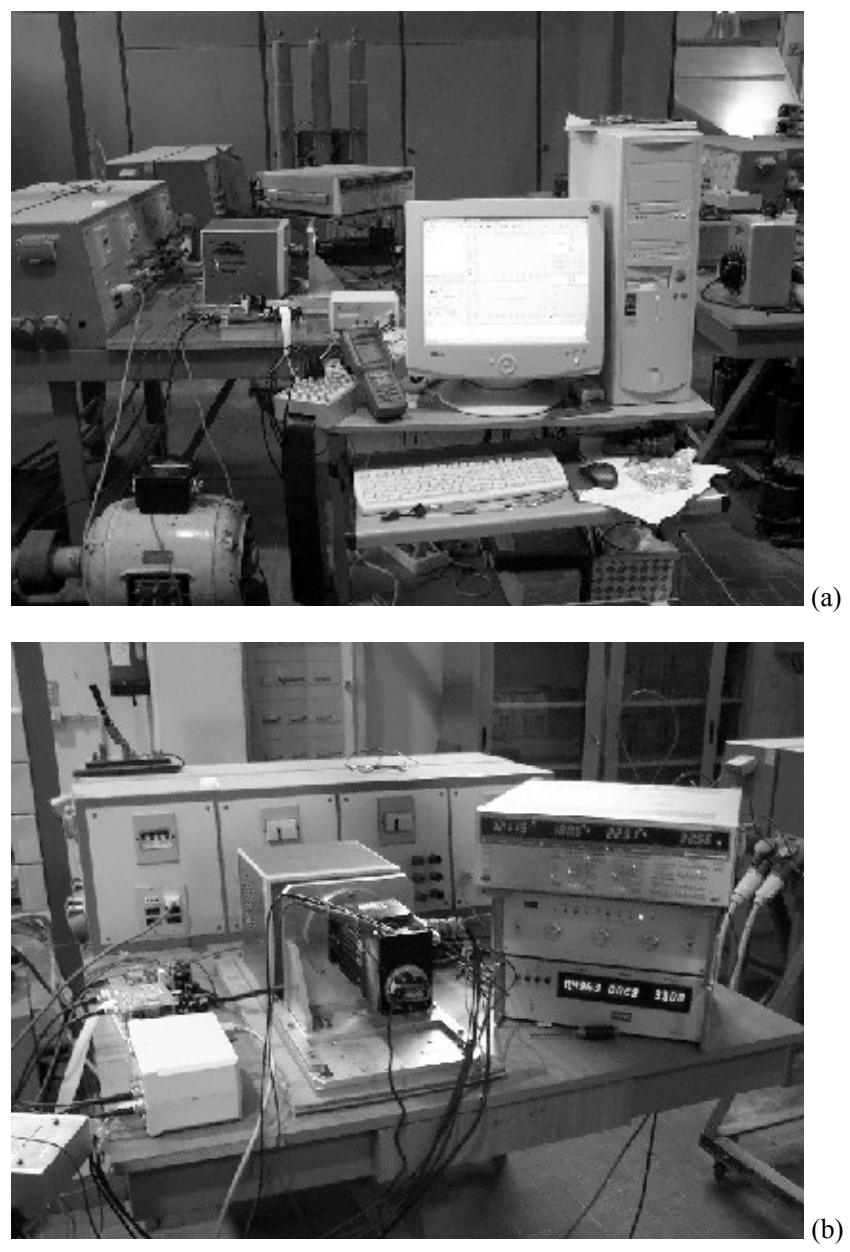

Fig. 4. (a) The test bench; (b) particular of the PMSM with the converter, the controlled brake and the power analyzer.

error and the LMA calculates the instantaneous values of $i_{d}$ and $i_{q}$ stator reference currents based on relations (5), (6) and 
(11). Obviously, based on the above discussion, the LMA inputs are the instantaneous angular speed and the reference torque coming out from the speed controller.

The LMA, the speed and the current loops have been implemented together on the dSPACE board. The output PWM signals generated from the dSPACE board are then directly fed to the drive circuits of IGBTs.

\section{EXPERIMENTAL RESULTS}

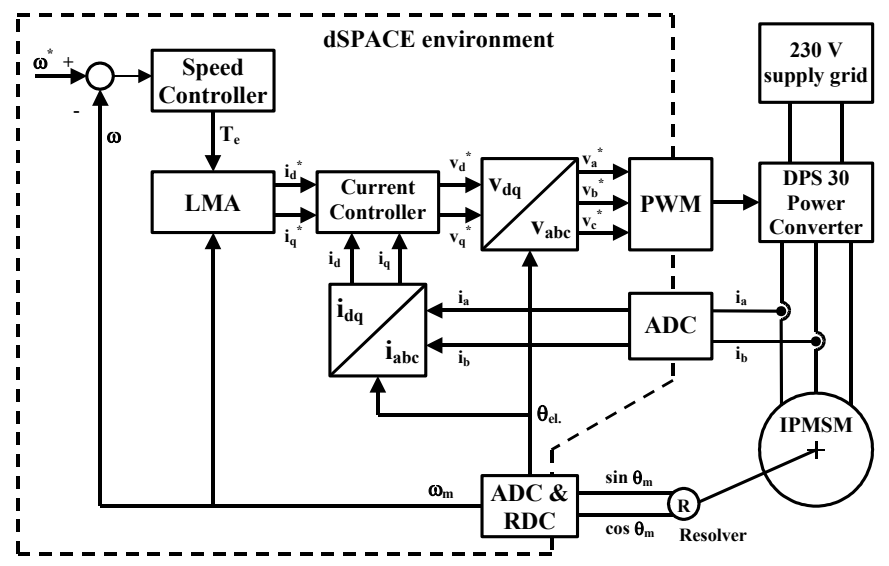

Fig. 5. Simplified schematic of the PMSM drive.

Extensive laboratory tests, obtained by using the above mentioned work bench, were carried out aiming to validate both relation (11) and the LMA on a PMSM drive. The characteristics of the PMSM and the power converter are listed respectively in Tables I and II. The most significant results are presented in this section.

In particular, the estimated power losses (winding, iron and overall controllable losses) and the measured ones relative to the PMSM drive are reported in Figs. 6 and 7 in the case of an angular speed of $3000 \mathrm{rpm}$, respectively at no load and full load conditions. The estimated power losses were calculated by applying (5), (6), (7), and (11). The measured power losses have been obtained as a difference between the PMSM input power and the brake output power. In this condition the

TABLE I

NAMEPLATE AND PERPHASE PARAMETERS OF THE PMSM

\begin{tabular}{ll}
\hline \hline Rated speed [rpm] & 4000 \\
Rated current (RMS) [A] & 3.6 \\
Rated torque [Nm] & 1.8 \\
Number of poles & 6 \\
Armature resistance $\mathrm{R}[\Omega]$ & 2.21 \\
Transversal resistance $\mathrm{R}_{\mathrm{c}}[\Omega]$ & 840 \\
Direct axis inductance $[\mathrm{mH}]$ & 9.77 \\
Quadrature axis inductance [mH] & 14.94 \\
Permanent magnet flux [Wb] & 0.0844 \\
Mechanical loss [Nm] & 0.04 \\
\hline \hline
\end{tabular}

TABLE II

ELECTRICAL CHARACTERISTICS OF THE IGBT POWER CONVERTER

\begin{tabular}{ll}
\hline \hline Input voltage (single phase) [V] & 230 \\
Motor supply rail (VDC) [V] & 310 \\
Output power peak [kW] & 6,5 \\
Phase current peak (crest) [A] & 30 \\
Phase current cont. (RMS) [A] & 21 \\
Switching frequency [kHz] & $5 \div 20$ \\
Shunt power peak [W] & 3200 \\
\hline \hline
\end{tabular}

controllable losses present a minimum at the direct axis current of about $i_{d}=-0.25 \mathrm{~A}$ (no load condition) and $i_{d}=-2.5 \mathrm{~A}$ (full load condition). Figs. 6 and 7 show also that the overall losses admit always a minimum, and it is, therefore, possible to find a value of the direct axis armature current that allows to obtain the maximum efficiency condition.

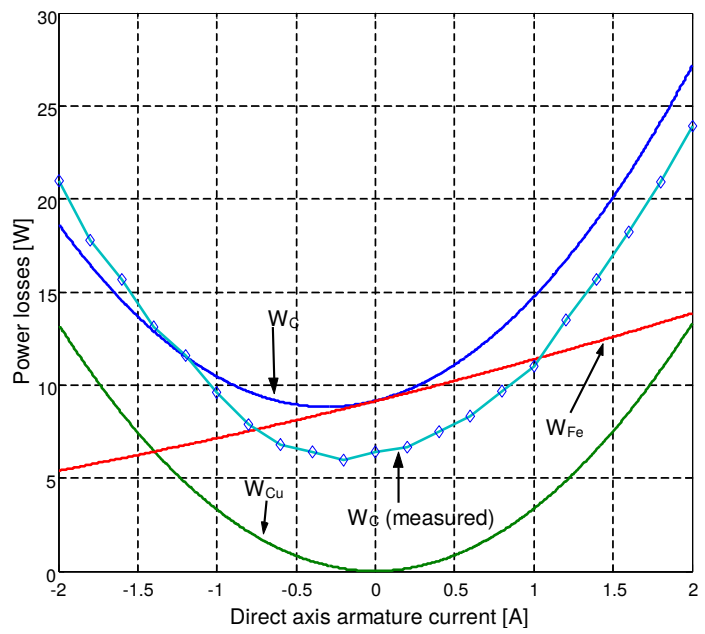

Fig. 6. Estimated and measured power losses of the test motor at $3000 \mathrm{rpm}$ and no load condition.

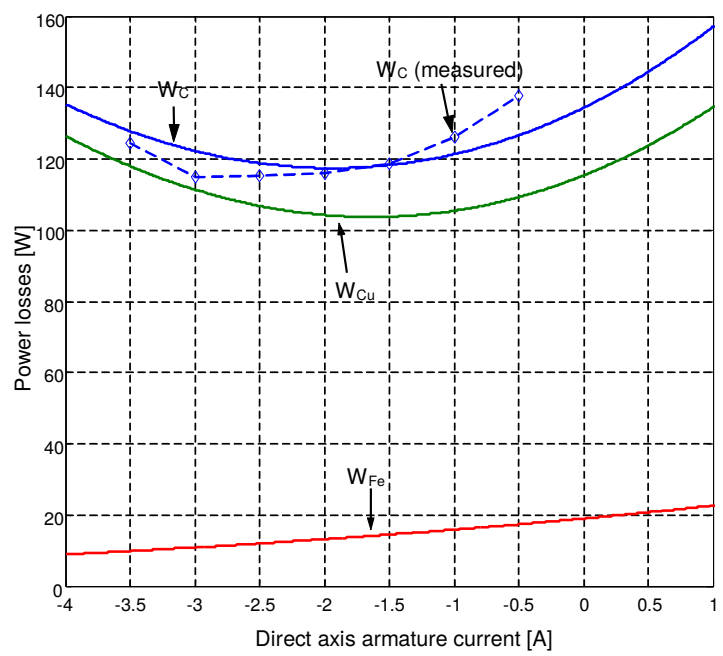

Fig. 7. Estimated and measured power losses of the test motor at $3000 \mathrm{rpm}$ and full load condition. 
Two tests were carried out in order to compare the LMA: the first one, which uses the LMA discussed in the preceding sections, the second one with a traditional $i_{d}=0$ control. The efficiency variation as a function of the mechanical speed in the case of LMA (continuous curve) and of $i_{d}=0$ control (dotted curve) is shown in Fig. 8 at the rated load of $1.8 \mathrm{Nm}$. The efficiency of the brushless motor increases up to $2.7 \%$, especially in the high speed range, where the iron losses become more intense as compared with those in the windings. Fig. 9 shows the efficiency improvement, with reference to the LMA case study, as a function of the angular speed in the same load condition of Fig. 8 .

It is worth to note that at high speed the effect of the flux

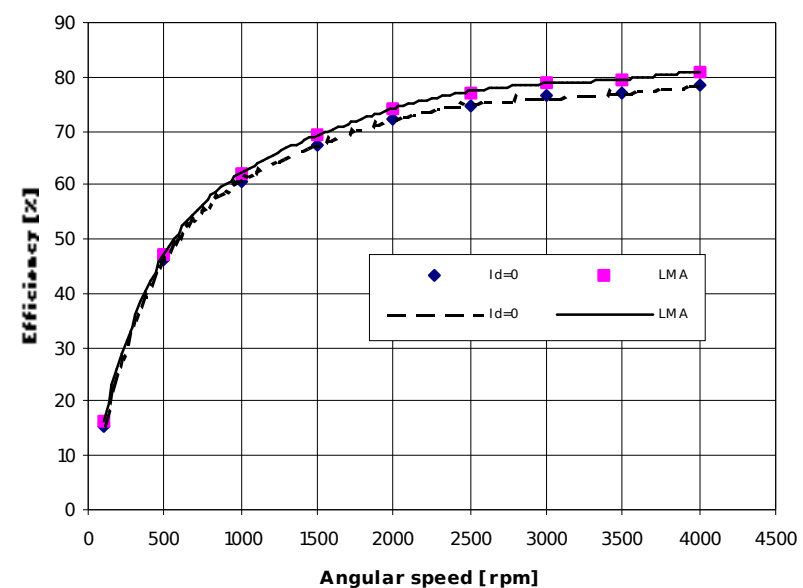

Fig. 8. Comparison of motor efficiencies at rated load $(1.8 \mathrm{Nm})$ as a function of the angular speed (rpm) in the case of LMA (continuous curve) and of $i_{d}=0$ control (dotted curve).

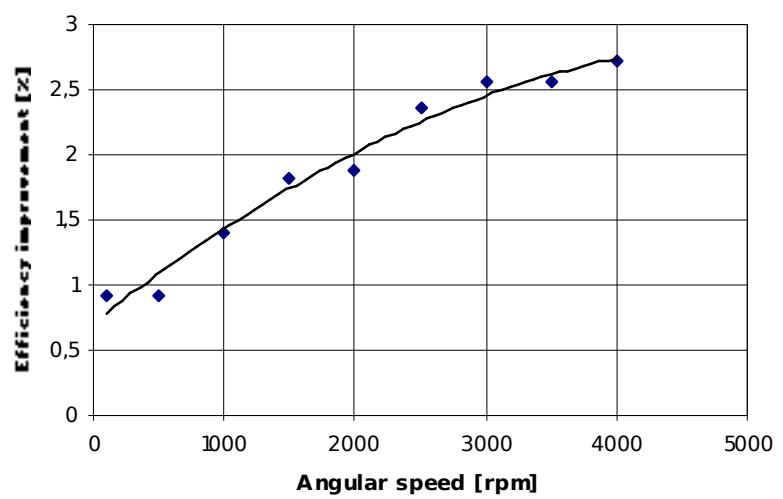

Fig. 9. Efficiency improvement due to LMA as a function of the angular speed at rated load condition $(1.8 \mathrm{Nm})$.

weakening significantly reduces the iron losses, while the increase (toward negative values) of the $i_{d}$ component of the stator current changes the reluctance torque component (see (7)) in order to maintain the whole electromagnetic torque quite constant. Fig. 10 shows the efficiency variations as a function of the mechanical load torque in the case of LMA (continuous curve) and of $i_{d}=0$ control (dotted curve) at the rated speed of $4000 \mathrm{rpm}$. By inspection of such a Fig. 10 it is possible to realize that the effectiveness of the LMA grows at increasing load.

Fig. 11 shows the improvement of the efficiency as a function of the load torque at the rated speed of $4000 \mathrm{rpm}$. A

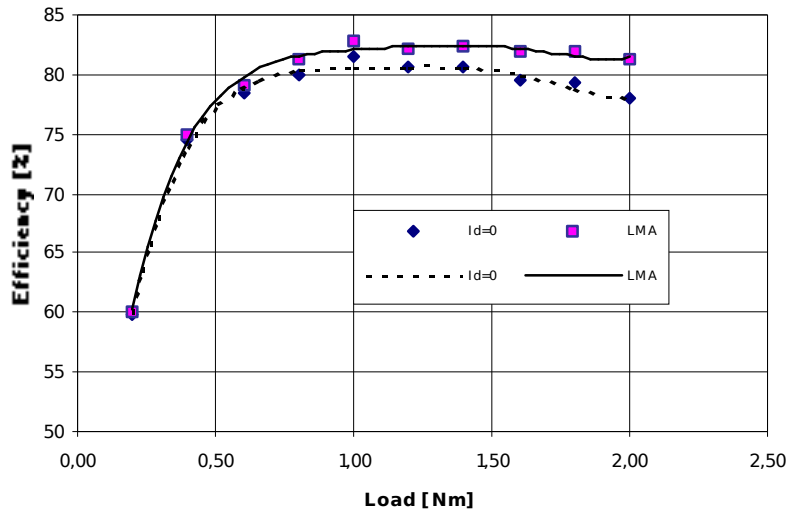

Fig. 10. Comparison of motor efficiencies at rated speed (4000 rpm) as a function of the mechanical load in the case of LMA (continuous curve) and of $i_{d}=0$ control (dotted curve).

significant efficiency improvement is then reached at high load and at high speed as expected. In fact, at a torque load of $2 \mathrm{Nm}$ (overload) the efficiency increase is about 3.5\%.

Fig. 12 reports the angular speeds versus time during a noload speed reversal from -3000 to $3000 \mathrm{rpm}$ of the PMSM electrical drive for both $i_{d}=0$ control and the LMA one. In

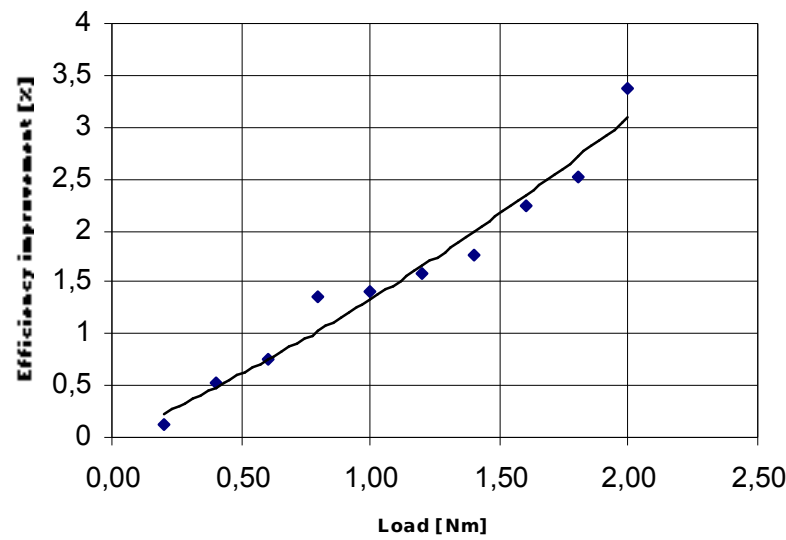

Fig. 11. Efficiency improvement due to LMA as a function of the load torque at rated speed (4000 rpm).

this case there is no appreciable difference, in the dynamic response of the speed between the traditional control algorithm and the loss minimization one. Finally, Fig 13 shows the direct and quadrature axis currents in the same test condition of Fig. 12. It can be seen that the dynamic of the currents is quite similar, while their instantaneous values are 
different.

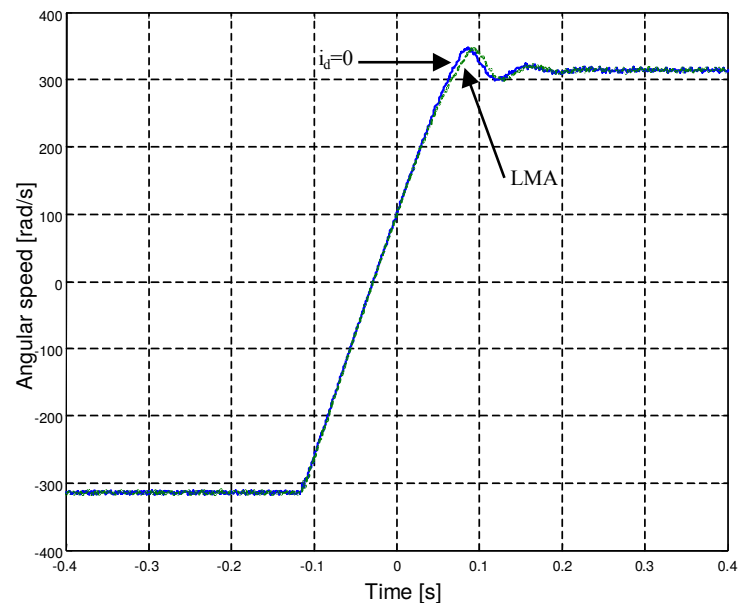

Fig. 12. Comparison of the dynamic performance of the PMSM motor drive during a speed reversal from -3000 to $3000 \mathrm{rpm}$ (-314 to $314 \mathrm{rad} / \mathrm{s})$.

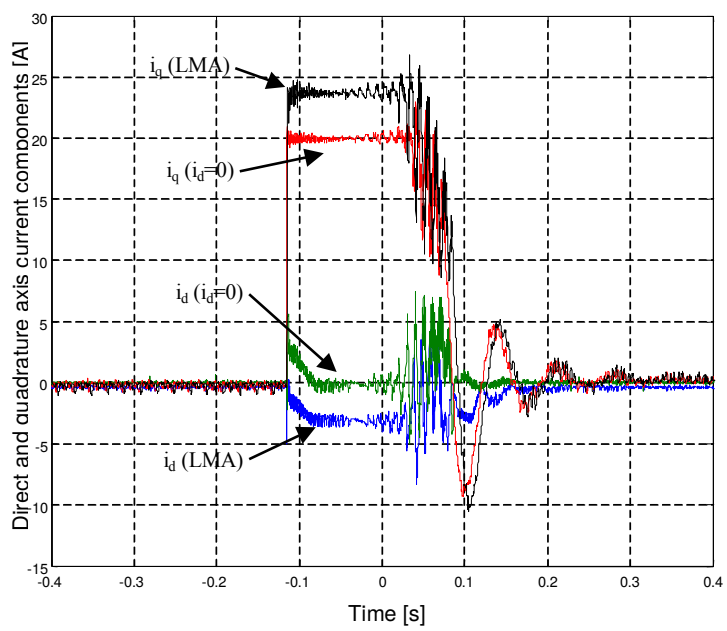

Fig. 13. Direct and quadrature motor current components during a speed reversal from -3000 to $3000 \mathrm{rpm}$.

\section{CONCLUSION}

In this paper a "loss-model" control strategy has been proposed. In particular, it has been verified by experimental tests that the control of the stator current space vector can minimize the controllable electrical losses occurring in a brushless motor drive. Such a control strategy, accounting for both the instantaneous speed values and the load torque condition, uses the combined effects of the field wakening and the exploitation of the reluctance torque. The loss minimization algorithm here reported is suitable for different brushless motor types, and it is very flexible and simple to implement because only requires the knowledge of some common motor parameters (like stator resistance, iron losses, direct and quadrature inductance's, etc.). The main results of the experimental tests carried out demonstrated how, in comparison with more traditional control methods, the loss minimization algorithm increments in a significant way the efficiency of a PMSM electrical drive without any reduction of the dynamic performances.

\section{LIST OF SYMBOLS}

$i_{d}, i_{q} \quad$ direct and quadrature axis current components;

$i_{c d}, i_{c q} \quad$ direct and quadrature axis iron loss current components;

$v_{d}, v_{q} \quad$ direct and quadrature axis voltage components;

$L_{d}, L_{q} \quad$ direct and quadrature axis inductances;

$L_{l d}, L_{l q} \quad$ direct and quadrature axis leakage inductance;

$L_{m d}, L_{m q}$ direct and quadrature axis magnetizing inductance;

$R, R_{c} \quad$ stator and transversal resistance;

$\lambda_{P M} \quad$ permanent magnet rotor flux;

$P \quad$ motor pole pairs;

$\omega_{r} \quad$ rotor mechanical angular speed;

$T_{e} \quad$ electromagnetic torque;

$T_{m} \quad$ load torque;

J rotor inertia;

C Coulomb friction factor;

$F \quad$ viscous friction factor;

$\theta_{r} \quad$ instantaneous rotor position.

\section{ACKNOWLEDGMENT}

This work was supported by MIUR (Ministry of University and Research) and C.N.R. (Italian Research Council).

\section{REFERENCES}

[1] S. Morimoto, Y. Tong, Y. Takeda, T. Hirasa, "Loss Minimization Control of Permanent Magnet Synchronous Motor Drives," IEEE Transaction on Industrial Electronics, Vol. 41, No. 5, October, 1994.

[2] S. Vaez, M. A. Rahaman, "Adaptive Loss Minimization Control of Inverter-Fed IMP Motor Drives," 28th Annual IEEE Power Electronics Specialists Conference, PESC '97, Vol. 2, pp. 861-868, 22-27 Jun 1997.

[3] T. M. Jahns, G. B. Kliman, T. W. Neumann, "Interior Permanent-Magnet Synchronous Motors for Adjustable-Speed Drives," IEEE Transaction on Industry Applications, Vol. IA-22, No. 4, pp. 738-747, July/August 1986.

[4] C. Cavallaro, A. O. Di Tommaso, R. Miceli, A. Raciti, G. Ricco Galluzzo, M. Trapanese, "Efficiency Improvement of Inverter-Fed Permanent Magnet Synchronous Motors," ${ }^{\text {rd }}$ International Conference on Energy Efficiency in Motor Driven Systems EEMODS'02, Treviso, Italy, 18-20 September 2002, pp. 490-497.

[5] Roy S. Colby, Donald W. Novotny, "Efficient Operation on SurfaceMounted PM Synchronous Motors," IEEE Transaction on Industry Applications, Vol. IA-23, No. 6, pp. 1048-1054, November/December 1987.

[6] Roy S. Colby, Donald W. Novotny, "An Efficiency-Optimizing Permanent Magnet Synchronous Motor Drive," IEEE Transaction on Industry Applications, Vol. 24, No. 3, pp. 462-469, May/June 1988.

[7] S. Morimoto, Y. Takeda, T. Hirasa, "Current Phase Control Methods for Permanent Magnet Synchronous Motors," IEEE Transaction on Industrial Electronics, Vol. 5, No. 2, pp. 133-139, April 1990.

[8] C. Mademlis, J. Xypteras, N. Margaris, "Loss Minimization in Surface Permanent-Magnet Synchronous Motor Drives," IEEE Transaction on Industrial Electronics, Vol. 47, No. 1, pp. 115-122, February 2000.

[9] F. Fernandèz-Bernal, A. Garcìa Cerrada, R. Faure, "Model-Based Loss Minimization for DC and AC Vector Controlled Motors Including Core Saturation," IEEE Transaction on Industry Application, Vol. 36, No. 3, May/Jun 2000, pp. 755-763.

[10] Byron S. Gottfried, Programming with Pascal, Ed. McGraw-Hill, 1985. 